\title{
Manejo de Gremmeniella abietina a través de agentes de control biológico y resistencia del hospedante
}

\author{
Romeralo Tapia, C. ${ }^{1,2^{*}}$ \\ ${ }^{1}$ Instituto Universitario de Investigación en Gestión Forestal Sostenible, Universidad de Valladolid-INIA, \\ Avenida Madrid 44, Edificio E, 34004, Palencia, España. \\ ${ }^{2}$ Departamento de Producción vegetal y Recursos Naturales, Universidad de Valladolid, \\ Avenida Madrid 44, Edificio E, 34004, Palencia, España. \\ *e-mail: carmen.romeralo@pvs.uva.es | carmenromeralo@gmail.com
}

\section{Resumen}

Gremmeniella abietina (Lagerberg) Morelet (anamorfo Brunchorstia pinea (P. Karst) v Höhn) es un hongo patógeno que produce daños severos en bosques y plantaciones de coníferas, causando la muerte de árboles en el centro y norte de Europa, en Norteamérica y en Japón. El patógeno fue detectado por primera vez en España en 1929 en árboles de pino marítimo (Pinus pinaster (Aiton)) y aislado en 1999 de masas de pino carrasco (Pinus halepensis (Mill)) en la provincia de Palencia. A pesar de que aún no se han registrado brotes epidémicos en España, causa problemas serios a los árboles que afecta. Los principales síntomas que produce son acículas secas, defoliación de la copa, distorsión de ramillos terminales y eventualmente la muerte de algunos pies. Las medidas de control en otros países para prevenir o reducir la expansión e incidencia de la enfermedad incluyen prácticas selvícolas como podar ramas o eliminar árboles muertos y la aplicación de fungicidas sin- 
téticos, aunque únicamente como medida de emergencia en viveros. La necesidad de gestión de la enfermedad junto con las recomendaciones europeas de usar métodos que no sean químicos, hacen necesario proveer de alternativas para luchar contra la enfermedad. Por ello, el principal objetivo de la presente tesis fue indagar en el uso de métodos alternativos para el control de las infecciones producidas por G. abietina. Para conseguir este objetivo, llevamos a cabo cuatro experimentos en los que se probó el uso de diferentes agentes de control biológico (hongos endófitos, sus filtrados y aislados infectados con virus) así como el uso de hospedantes resistentes.

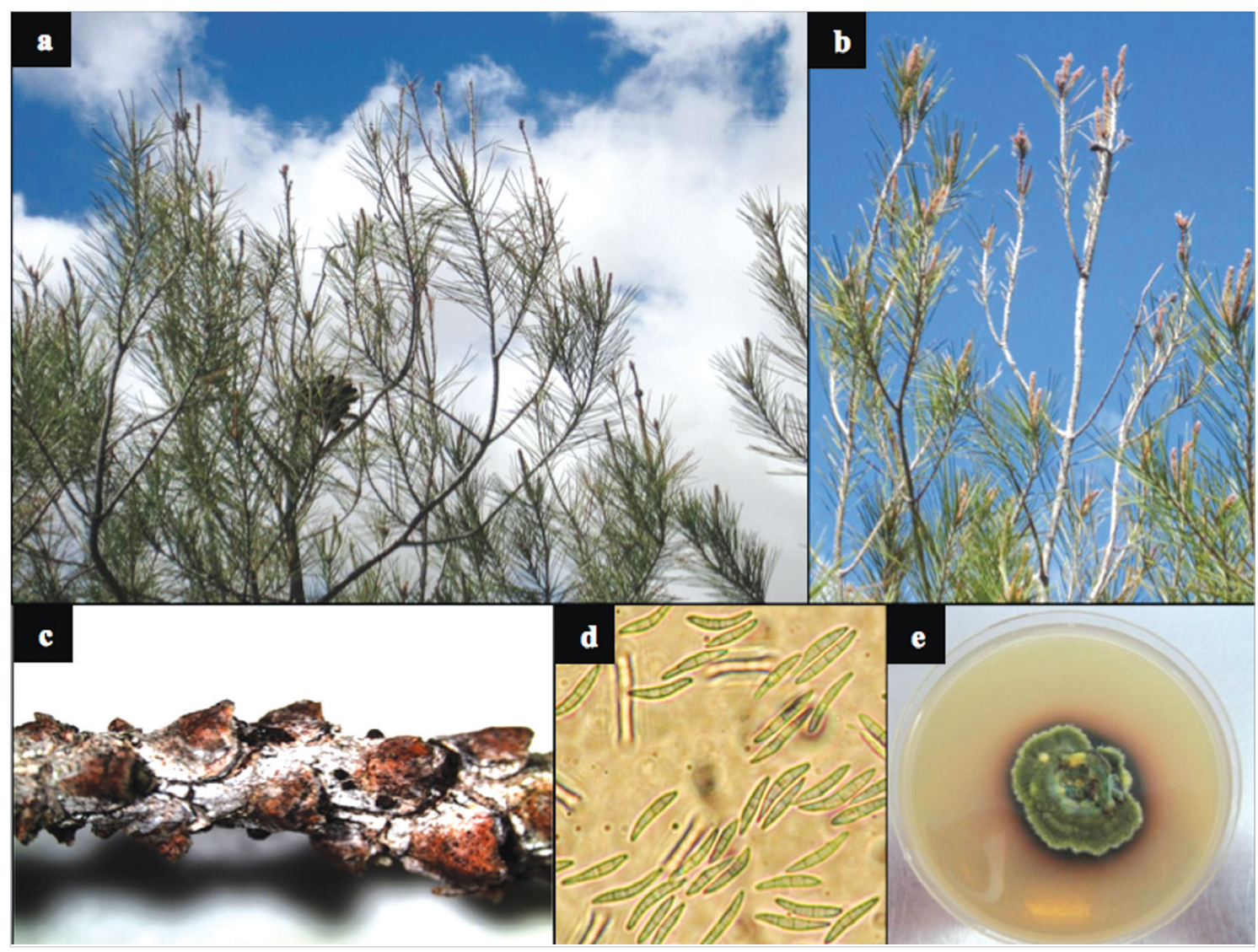

Figura 1. Síntomas de Gremmeniella abietina en las masas españolas: a defoliación; b distorsión ramillos terminales; $\mathbf{c}$ cuerpos de fructificación; $\mathbf{d}$ conidios; e micelio en cultivo puro

Los dos primeros experimentos se realizaron con hongos endófitos y sus filtrados, ya que se había comprobado previamente que estos organismos eran capaces de reducir o inhibir el crecimiento de diferentes patógenos a través de varios mecanismos. Los endófitos (primer experimento) y sus filtrados (segundo) se aplicaron a plantas de pino carrasco junto con los aislados de G. abietina para producir la infección. Además, para explorar los mecanismos que emplean estos agentes de control biológico para luchar contra el patógeno, se midió la concentración de fenoles totales en las plantas tras la infección, como un indicador de la activación del sis- 
tema de defensa de la planta. También se midió el contenido en compuestos fenólicos de los filtrados para explorar la posible presencia de sustancias antibióticas. Al final del experimento ( 6 meses después de las inoculaciones) las necrosis producidas por el avance del patógeno se midieron en todas las plantas. Los experimentos se repitieron tres semanas después de la primera inoculación para verificar los resultados. La presencia de todos los endófitos usados en nuestros experimentos así como sus filtrados redujo de forma significativa el avance de G. abietina en las plantas aunque dependió del momento de la inoculación. Cuando se usaron los endófitos como agentes de control biológico, el contenido en fenoles totales de la planta no aumentó. Por tanto, los mecanismos responsables de esta reducción pudieron ser la competición, el parasitismo, la producción de compuestos antibióticos o una combinación de ellos. Además, algunos compuestos fenólicos fueron detectados en varios de los filtrados aunque no en todos, sugiriendo que aunque quizá la antibiosis estuviera implicada en esta reducción, los endófitos probablemente empleen varios mecanismos de acción.

En el tercer experimento, se probó si la presencia de mitovirus (virus del género Mitovirus que están asociados con hongos y cuya presencia a veces se relaciona con una disminución de la patogenicidad del mismo) en los aislados de G. abietina, era capaz de modificar su comportamiento y patogenicidad del hongo tanto en condiciones in vitro como in vivo en plantas de pino carrasco. Los resultados mostraron que los aislados infectados con mitovirus presentaron un mayor crecimiento micelial que los no infectados a la temperatura óptima de crecimiento del hongo que son $15^{\circ} \mathrm{C}$. En el experimento del invernadero se observó que las plantas que habían sido inoculadas con aislados con virus, presentaron mayores necrosis, sugiriendo que la presencia de virus en aislados de G. abietina podría estar produciendo una hipervirulencia del patógeno.

Por último, en el cuarto experimento, se realizó un ensayo de procedencias de pino carrasco para estudiar si alguna de ellas era resistente a la enfermedad. La necrosis producida por el avance del patógeno en la planta fue usada como variable respuesta. Además, las concentraciones de dos flavanonas se midieron como posibles indicadores de la resistencia en plantas a la enfermedad. Las procedencias de pino carrasco evaluadas mostraron diferencias significativas en su susceptibilidad al patógeno en términos de necrosis y severidad visual. La cantidad de la flavanona naringenina fue diferente entre procedencias, sugiriendo que es un posible indicador de la resistencia.

Las principales conclusiones de la Tesis Doctoral fueron que el uso de hongos endófitos así como sus filtrados podría ser apropiado para reducir la incidencia de fitopatógenos como G. abietina en plántulas de pino. Parece que los mecanismos empleados por los endófitos para luchar contra G. abietina fueron la competición o la antibiosis, más que la activación del sistema de defensa inducida de la planta. Sin embargo, se observaron algunas variaciones temporales en las respuestas, indicando la complejidad del sistema. Por otra parte, la presencia de mitovirus en los aislados de G. abietina produjo un incremento del crecimiento del patógeno en condiciones de laboratorio favorables para su desarrollo y un aumento de su virulencia en las 
inoculaciones in planta, indicando una posible hipervirulencia del mismo. Por último, nuestros resultados sugirieron que para mejorar la sostenibilidad de las plantaciones de pino carrasco en el futuro se recomienda evaluar con anterioridad la resistencia a la enfermedad de las diferentes procedencias. Además, se podrían encontrar marcadores de la resistencia del árbol al patógeno entre el conjunto de compuestos químicos que se generan como consecuencia de la infección.

\section{Datos de la tesis}

Premio DoctorsTC 2015

Director: Julio Javier Diez Casero.

Centro: Instituto Universitario de Investigación en Gestión Forestal Sostenible Universidad de Valladolid-INIA.

Fecha de defensa: Octubre 2015

\section{Publicaciones derivadas de la tesis doctoral}

Romeralo C., Witzell J., Diez J.J. (2015). Aleppo pine provenances vary in susceptibility and secondary chemical response to Gremmeniella abietina infection. Plant Pathology. Doi: 10.1111/ppa.12452.

Romeralo C., Witzell J., Romeralo-Tapia R., Botella L., Diez J.J. (2015). Antagonistic activity of fungal endophyte filtrates against Gremmeniella abietina infections on Aleppo pine seedlings. European Journal of Plant Pathology. Doi: 10.10007/ s10658-015-0719-3.

Romeralo, C., Pando, V., Santamaria, O., Diez, J.J. (2015). Fungal endophytes reduce necrosis length produced by Gremmeniella abietina in Pinus halepensis seedlings. Biological Control 80: 30-39.

Romeralo, C., Botella, L., Santamaria, O., Diez, J.J. (2012). Effect of putative mitoviruses on in vitro growth of Gremmeniella abietina isolates under different laboratory conditions. Forest systems 21 (3) 515-525. 